\title{
Modulation of Dendritic Cell Maturation by Fasciola hepatica: Implications of glycans and mucins for Vaccine Development
}

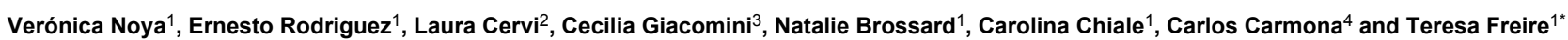

${ }^{1}$ UdelaR, Facultad de Medicina, Department of Inmunobiología, Immunomodulation and vaccine development, Gral, Flores 2125, CP11800, Montevideo, Uruguay

2Universidad Nacional de Córdoba, Facultad de Ciencias Químicas, Department of Bioquímica Clínica, CIBICI-CONICET, Córdoba, Argentina, Haya de la Torre y Medina Allende, 5000 Córdoba, Argentina

${ }^{3}$ UdelaR, Facultad de Química, Department of Biociencias, Cátedra de Bioquímica, Gral, Flores 2124, CC 1157, Montevideo, Uruguay

${ }^{4}$ UdelaR, Facultad de Ciencias, Instituto de Higiene, Department of Biología Celular y Molecular, Unidad de Biología Parasitaria, Av. A. Navarro 3051 CP11600, Montevideo, Uruguay

*Corresponding author: Teresa Freire, UdelaR, Facultad de Medicina, Department of Inmunobiología, Gral, Flores 2125, 11800, Montevideo, Uruguay, Tel: 5982924 9562; Fax: 5982924 9563; E-mail: tfreire@fmed.edu.uy

Received date: 11 April 2014; Accepted date: 26 May 2014; Published date: 01 June 2014

Copyright: @ 2014 Noya $\vee$ et al. This is an open-access article distributed under the terms of the Creative Commons Attribution License, which permits unrestricted use, distribution, and reproduction in any medium, provided the original author and source are credited.

\begin{abstract}
Fasciola hepatica is a worldwide distributed helminth pathogen that causes great economic losses in sheep and cattle. This parasite is able to regulate the host immune response, producing high levels of IL-5 and low levels of IFNy, as well as modulating the function of dendritic cells (DCs), mast cells or macrophages, among others. Moreover, TLR-mediated maturation of DCs can be suppressed by F. hepatica derived components. Here, we investigated the role of glycans in the modulation of LPS-induced maturation of DCs, as well as in the production of IL-5 and IFNy by splenocytes from infected mice. We show that $F$. hepatica induces the recruitment to the peritoneum of semi-matured DCs, as judged by a down-regulation of MHC class II molecule expression and an increase of CD80 and CD86 expression of DCs in the peritoneum of infected animals. Furthermore, we provide evidence indicating that glycan structures from $F$. hepatica are responsible, at least in part, for inhibiting LPSinduced DC maturation and production of IFNy by splenocytes from infected animals. On the other hand, we show that a mucin-like non-glycosylated peptide highly expressed in NEJ (Fhmuc) is able to synergize with LPS in inducing DC-maturation, and that it induces a T cell response specific for $F$. hepatica, both alone or in combination with DCs. Our data highlight the role of $F$. hepatica glycans in modulating the host immune response and might contribute to the design of vaccines against fasciolosis.
\end{abstract}

Keywords: Fasciola hepatica; Glycan; Mucin; Dendritic cell

\section{Abbreviations:}

BMDCs: Bone Marrow Derived Dendritic Cells; DCs: Dendritic Cells; FhTE: F. hepatica Total Extract; FhPox: F. hepatica Oxidized Total Extract; FhB: F. hepatica Borohydride-Treated Total Extract; ND: Not Done; MHC: Major Histocompatibility Complex; SD: Standard Deviation; TLR: Toll-Like Receptor.

\section{Introduction}

Fasciolosis is a major parasitic disease of livestock causing significant economic losses worldwide [1]. Currently, fasciolosis is also considered an emerging zoonoses with increasing number of people infected around the world [1]. In temperate regions this disease is caused by the liver fluke Fasciola hepatica. During infection, this pathogen induces potent polarized Th2/Treg immune responses, suppressing the production of Th1 cytokines [2-5]. Thus, the parasite is able to modulate the host immune response by increasing the production of IL-4, IL-5, IL-10 or TGF $\beta[2,6]$, and inhibiting the levels of IFN $\gamma$ or IL-17 [2,5].

This strategy allows the parasite establish chronic infections and prolongs its survival in the host. In this context, liver fluke infection has shown to increase susceptibility to other infectious diseases, such as bovine tuberculosis thus affecting the efficacy of control programs [7].

Many lines of evidence indicate that the evasion immune mechanisms that are utilized by helminths, including Fasciola, comprise, for instance, the modulation of maturation and function of dendritic cells (DCs) [8-10], the impairment of mast cell activation [11-12], an increase of regulatory $\mathrm{T}$ cells $\left(\mathrm{T}_{\text {regs }}\right)$ [2], the alternative activation of macrophages [13], the production of immunesuppressive cytokines by the host [6], the proteolytic cleavage of antibodies by parasite proteases [14], or the apoptosis of eosinophils [15] or macrophages [16], and are subject of ongoing investigation nowadays.

DCs are potent antigen presenting cells that possess the ability to stimulate naive T cells. In response to infectious agents DCs undergo a maturation process during which they migrate to secondary lymphoid organs where they present captured antigens to naive $\mathrm{T}$ cells, for the triggering of specific immunity. This process is associated to an upregulation of the expression of MHC molecules, adhesion molecules and co-stimulatory molecules as well as a down-regulation of their endocytotic capacity [17].

DCs matured in the presence of helminth antigens express reduced levels of co-stimulatory markers (CD40, CD80 or CD86) and MHC class II molecules, as compared to DCs matured with Toll-like receptor (TLR) ligands such as lipopolysaccharide (LPS) [18]. Also, 
Citation: Noya V, Rodriguez E, Cervi L, Giacomini C, Brossard N, et al. (2014) Modulation of Dendritic Cell Maturation by Fasciola hepatica: Implications of glycans and mucins for Vaccine Development. J Vaccines Vaccin 5: 233. doi:10.4172/2157-7560.1000233

Page 2 of 8

these DCs are not capable of producing high levels of proinflammatory cytokines (IL-12, IL-6 or TNFa) [18]. In this sense, independent in vitro studies have reported that different Fasciola hepatica components suppress TLR-initiated DC maturation and their stimulatory function [8-10].

Helminths express various carbohydrates-containing glycoconjugates on their surface and they release glycan-rich excretion/secretion products that can be very important in their life cycles and pathology [19]. Carbohydrate-signatures from parasites are decoded by the immune system through the interaction of several immune receptors. In particular, receptors of the innate branch that recognize glycan motifs consist of soluble or membrane-associated lectins, siglecs and scavenger receptors, among others. Notably, C-type lectin receptors (CLRs) have been described to mediate internalization of parasite glycosylated molecules as well as cell-surface signaling [20]. Certain helminth parasites also express mucin-like molecules, the major carriers of $O$-glycans [21]. They can participate in attachment and invasion of host cells among other processes, by providing resistance to proteolytic attack or avoiding immune recognition [21]. Interestingly, the CLR Dectin- 1 seems to mediate the recognition of $F$. hepatica glycans and may be involved in the alternative activation of macrophages [22].

Little is known about the glycans produced by $F$. hepatica, with only two reports describing lectin reactivity in the miracidial surface [23] or in the gut of adult flukes [24], suggesting the presence of mannose and glucose residues, and other describing Gal $\beta 1-6 \mathrm{Gal}$-terminating glycolipids by mass spectrometry [25]. Also, our group has previously described, the expression of the GalNAc-O-Ser/Thr structure (known as Tn antigen) [26]. Recently, during a characterization of the transcriptome of $F$. hepatica newly excysted juveniles (NEJ) a cDNA clone coding for a mucin-like protein highly expressed in the infected stage, has been identified [27].

In this paper we evaluate the role of $F$. hepatica glycans at a systemic level and show that glycans inhibit IFN $\gamma$ production of specific splenocytes from infected animals. Furthermore, we show that $F$. hepatica induces a recruitment of DCs to the peritoneum during infection and modulates DC activation judged by a down-regulation of MHC class II molecule expression in infected animals. In vitro, we demonstrate that this DC-immunomodulation can be mediated by glycans. Finally, we evaluate the immunological properties of a mucinlike peptide (Fhmuc) highly expressed in juveniles, and present preliminary data indicating that this mucin-like peptide is able to induce parasite-specific Th1-polarized cell response. Moreover, when administered in combination with DCs, the IFN $\gamma$ producing $\mathrm{T}$ cells immune response is stronger, since it synergizes with LPS in inducing DC-maturation, suggesting that it could constitute a good vaccine candidate.

\section{Materials and Methods}

\section{Mice}

Six- to 8-week-old female C57BL/6 or BALB/c mice were obtained from DILAVE Laboratories (Uruguay). Animals were kept in the animal house (URBE, Facultad de Medicina, UdelaR, Uruguay) with water and food supplied ad libitum, and handled in accordance with institutional guidelines for animal welfare by the Committee on Animal Research (Comisión Honoraria de Experimentación Animal, CHEA, Uruguay).

\section{Preparation of protein lysates from $F$. hepatica}

Live adult worms of $F$. hepatica were obtained from the bile ducts of bovine livers and then washed for $1 \mathrm{~h}$ at $37^{\circ} \mathrm{C}$ with phosphate buffered saline (PBS) $\mathrm{pH}$ 7.4. Total parasite lysates (FhTE) were prepared by incubation of washed adults flukes in PBS, sonicated and centrifuged at $40,000 \times \mathrm{g}$ for $60 \mathrm{~min}$. Carbohydrate glycol groups present in FhTE were oxidized with sodium periodate $(10 \mathrm{mM})$. The oxidation was performed at room temperature for 45 minutes, followed by the reduction with sodium borohydride $(100 \mathrm{mM})$ of the reactive aldehyde groups. The resulting oxidized lysate is referred as FhPox. In order to perform control experiments, the following control extracts were prepared: FhB, consisted of FhTE subjected to the whole treatment excepting for the incubation with sodium periodate; and CPox, consisting in PBS subjected to the entire treatment. Lysates were dialyzed against PBS and their protein concentration was measured using the bicinchoninic acid assay (Sigma, St. Louis, MO, USA). To remove endotoxin contamination, FhTE was applied to a column containing endotoxin removing gel (detoxi-gel, Pierce Biotechnology). The endotoxin levels were determined by using the Limulus Amebocyte Lysate kit Pyrochrome (Associates of Cape Cod). Protein preparations showed very low levels of endotoxins and were not able to induce DC maturation (as IL-12 read out) on their own. The concentration of $F$. hepatica extracts used in culture experiments did not modify cell viability.

\section{Infections and cell culture}

Animals (5 per group) were orally infected with 5 (for BALB/c) or 10 (for C57BL/6) F. hepatica metacercariae (Baldwin Aquatics, USA) per animal. After 3 weeks of infection spleens and peritoneal exudates cells (PECs) were removed. PECs were harvested by washing the peritoneal cavity with $10 \mathrm{~mL}$ of PBS. Splenocytes or PECs $\left(0.5-1 \times 10^{6}\right.$ cells $/ \mathrm{mL}$ ) were cultured in complete medium consisting of RPMI- 1640 with glutamine (PAA Laboratories, Austria) supplemented with $10 \%$ heat-inactivated fetal bovine serum (FBS), $50 \mu \mathrm{M}$ 2-mercaptoethanol, $100 \mathrm{U} / \mathrm{ml}$ penicillin and $100 \mathrm{mg} / \mathrm{ml}$ streptomycin (Sigma, St. Louis, MO, USA), in the presence or absence of FhTE $(75 \mu \mathrm{g} / \mathrm{ml})$, FhPox (75 $\mu \mathrm{g} / \mathrm{ml})$, Fhmuc $(10 \mu \mathrm{g} / \mathrm{ml})$ and the controls FhB or CPox, for $72 \mathrm{~h}$ at $37^{\circ} \mathrm{C}$ and $5 \% \mathrm{CO} 2$. IFN $\gamma$ and IL-5 levels were tested on culture supernatants by interleukin- specific sandwich ELISA assays (BD Bioscience, NJ, USA). Uninfected naive animals were used as a control group.

\section{T cell response}

A 66 amino acid sequence of a F. hepatica mucin like-protein, named Fhmuc, was synthesized by Peptide 2.0 Inc (Virginia, USA). The amino acid sequence of the peptide isVSSDASTTSTTMTARSSSASATASSETRAPSSTMTTQNASTTSGS VRLPIQTTRCILLFIFG VAFF.

Mice were immunized intraperitoneally (i.p.) with Fhmuc $(10 \mu \mathrm{g})$ in complete or incomplete Freund's adjuvant, at days 0, 14, 28. Two weeks after the last immunization mice were sacrificed and spleens and PECs were removed. Cells were dispersed manually and centrifuged at 1,500 rpm for $5 \mathrm{~min}$. Cells $\left(1 \times 10^{6} /\right.$ well $)$ were suspended in complete culture medium and cultured for $72 \mathrm{~h}$ at $37^{\circ} \mathrm{C}$ and $5 \%$ CO2 in 96-well plates with Fhmuc peptide $(10 \mu \mathrm{g} / \mathrm{ml})$, FhTE $(50 \mu \mathrm{g} /$ $\mathrm{ml}$ ), or medium alone. Secreted cytokine (IFN $\gamma$, IL-5) levels were tested on culture supernatants by interleukin- specific sandwich ELISA assays (BD Bioscience, NJ, USA). 
Citation: Noya V, Rodriguez E, Cervi L, Giacomini C, Brossard N, et al. (2014) Modulation of Dendritic Cell Maturation by Fasciola hepatica: Implications of glycans and mucins for Vaccine Development. J Vaccines Vaccin 5: 233. doi:10.4172/2157-7560.1000233

Page 3 of 8

\section{Cell analyses by flow cytometry}

Splenocytes or PECs from infected and non-infected mice were washed twice with PBS containing $2 \%$ FBS and $0.1 \%$ sodium azide. Cells were then stained with different antibody mix to identify $\mathrm{B}$ and $\mathrm{T}$ cells [anti-CD3 (17A2), -CD4 (RM4-5), -CD8a (53-6.7), -CD19 (eBio1 D3)]; NK cells [anti-NK1.1-PE (PK136), -CD69-FITC (H1.2F3) and CD49b-APC (DX5)]; regulatory T cells [CD4 (RM4-5), -CD25 (PC61.5), -FoxP3 (FJK-16s)]; dendritic cells and macrophages [antiCD11b (M1/70), -CD11c (N418), -CD40 (HM40-3), -MHC II (m5/114.15.2), I-A/I-E (2G9), -F4/80 (BM8), -CD80 (16-10A1), -CD86 (GL1)]; or monocoytes and granulocytes [anti-CD11b (M1/70), Ly-6G (RB6-8C5), -Ly-6C (HK1.4), -Siglec-F (E50-2440)]. Cells were then washed twice with PBS containing 5\% FBS and $0.1 \%$ sodium azide and fixed with $1 \%$ formaldehyde. Cell populations were analyzed using a CyAn ADP Analyzer (Beckman Coulter). Antibodies were obtained from eBioscience or from BD-Biosciences.

\section{Dendritic cell maturation}

Bone Marrow-derived Dendritic Cells (BMDCs) were generated from bone marrow precursors from $\mathrm{BALB} / \mathrm{c}$ or $\mathrm{C} 57 \mathrm{BL} / 6$ mice. Briefly, bone marrow precursor cells were harvested and plated at a density of $2-5 \times 10^{5}$ cells $/ \mathrm{ml}$ in complete culture medium supplemented with GMCSF-containing supernatant. After 3 days of culture at $37^{\circ} \mathrm{C}$, the medium was replaced. Cells were recovered on day 8 and analyzed for the expression of $\mathrm{CD} 11 \mathrm{c}$ by flow cytometry. To induce DCmaturation, BMDCs $\left(2.5 \times 10^{5} /\right.$ well $)$ were incubated at $37^{\circ} \mathrm{C}$ and $5 \%$ $\mathrm{CO}_{2}$ in 96-well plates with FhTE, FhPox, FhB $(75 \mu \mathrm{g} / \mathrm{ml})$ or Fhmuc (10 $\mu \mathrm{g} / \mathrm{ml}$ ) or medium alone in the presence or absence of LPS (Escherichia coli 0111:B4, 0.5-1 $\mu \mathrm{g} / \mathrm{ml}$ ), Zymosan-A (from $S$. cerevisiae, $1 \mu \mathrm{g} / \mathrm{ml})$ or poly:(IC) $(50 \mu \mathrm{g} / \mathrm{ml})$ overnight at $37^{\circ} \mathrm{C}$. Cells were then centrifuged at $1,500 \mathrm{rpm}$ for $5 \mathrm{~min}$ at $4^{\circ} \mathrm{C}$ and supernatants were then collected. Cytokine (IL-12/23p40, IL-10 and IL-6) levels were tested on culture supernatants by interleukin specific sandwich ELISA assays (BD Bioscience, NJ, USA). Results are expressed in $\mu \mathrm{g} / \mathrm{ml}$.

To evaluate the capacity of BMDCs treated with Fhmuc and LPS to stimulate $F$. hepatica specific T cells in vivo, loaded-BMDCs were washed three times in culture medium, and then inoculated i.p. into mice $\left(1 \times 10^{6}\right.$ cells/mouse). Ten days later, spleens and PECs were removed and cultured in the presence of Fhmuc $(10 \mu \mathrm{g} / \mathrm{ml})$ or FhTE $(50 \mu \mathrm{g} / \mathrm{ml})$ for $72 \mathrm{~h}$ at $37^{\circ} \mathrm{C}$. IFN $\gamma$ or IL- 5 were detected on culture supernatants by specific ELISAs.

\section{Model of septic shock}

Groups of four C57BL/6 mice were injected i.p. with Fhmuc (10 $\mu \mathrm{g} /$ mouse) $2 \mathrm{~h}$ before i.p. injection with LPS ( $1 \mu \mathrm{g} / \mathrm{mouse})$. Control mice received PBS or Fhmuc in absence of LPS, or PBS plus LPS. Mice were sacrificed $6 \mathrm{~h}$ later and bled. Serum concentrations of IFN $\gamma$ and IL-12/23p40 were measured by specific ELISAs.

\section{Statistical Analysis}

The Student $\mathrm{t}$ test was used for statistical comparisons; $\mathrm{p}$ values $<0.01$ or $<0.05$ were considered to be statistically significant, depending on the experiment.

\section{Results}

\section{Glycans produced by $\boldsymbol{F}$. hepatica modulate production of IFN $\gamma$ by splenocytes from infected animals}

Helminths, and in particular $F$. hepatica, induce potent polarized Th2/Treg immune responses, suppressing the production of Th1 cytokines [2-5]. Glycans are abundant on helminth surfaces as well as in their excretory/secretory products [28] and can regulate or suppress the host immune response to guarantee their survival [29]. In order to evaluate whether $F$. hepatica glycans play a role in the modulation of the host immune response at a systemic level, we evaluated the ability of spleen cells from infected mice to produce IFN $\gamma$ when re-stimulated with a total parasite extract presenting intact (FhTE) or oxidized (FhPox) glycans. To this end, we carried out a mild periodate oxidation of glycol groups in carbohydrates to reactive aldehyde groups, which are in turn reduced with sodium borohydride. Thus, the structure of carbohydrates is lost, as well as the possible biological activity that they can mediate. In agreement with previous results, splenocytes from infected animals stimulated in vitro with $\mathrm{F}$. hepatica total extract (FhTE) produced only IL-5 (Figure 1A). In contrast, when these cells were stimulated with oxidized FhTE (FhPox) they acquired the capacity of producing IFN $\gamma$ (Figure 1B), suggesting a role of glycans in the inhibition of IFN $\gamma$ by specific splenocytes. The control FhB consisting in FhTE subjected to the whole treatment excepting for the incubation with sodium periodate, induced the production of IL-5 in absence of IFN $\gamma$, as the FhTE, while the CPox, representing PBS subjected to the entire treatment did not induce the production of either IL-5 or IFN $\gamma$, as expected.

\section{Infection with $F$. hepatica is associated to an increase of dendritic cells, macrophages, eosinophils and regulatory $T$ cells in the peritoneal cavity}

Considering that the periodate oxidation of glycans allowed the production of IFN $\gamma$ by specific-T cells in the spleens from infected animals, we sought to characterize the lymphoid, as well as the myeloid immune cells in these mice and determine whether $F$. hepatica modulates the recruitment or activation of immune cells. Thus, we carried out an extensive immunophenotyping of splenocytes and cells from the peritoneum (PECs) from infected-mice by flow

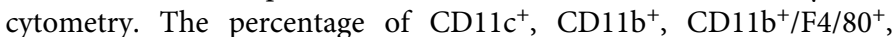

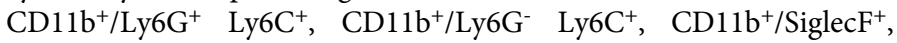
$\mathrm{CD}_{1}{ }^{+} \mathrm{CD}^{-}, \mathrm{CD}^{+}{ }^{+} \mathrm{CD} 4^{+}, \mathrm{CD}^{+} \mathrm{CD}^{+}$or $\mathrm{CD} 4^{+} / \mathrm{CD} 25^{+} \mathrm{FoxP}^{+}$cells were determined in mice sacrificed after three weeks post-infection, and compared to naïve animals.

Although the levels of T or B lymphocytes did not vary significantly, except for $\mathrm{CD} 3+\mathrm{CD} 8+\mathrm{T}$ cells that were augmented in the peritoneum and CD19+ B cells in the spleen, their activation status defined by the expression of CD62L was considerably different (Figure 2). Lymphocytes from the spleen of infected animals had lower levels of CD62L expression than naive animals, while $\mathrm{B}$ or $\mathrm{T}$ cells from the peritoneum up-regulated expression of $\mathrm{CD} 62 \mathrm{~L}$, indicating that lymphocytes in the spleen were activated following infection, while naïve $\mathrm{B}$ and $\mathrm{T}$ cells were recruited at the peritoneum. Interestingly, regulatory $\mathrm{T}$ cells (Tregs) defined as $\mathrm{CD} 4+/ \mathrm{CD} 25+$ FoxP3+ were augmented in the spleen (Figure 2), which could be in agreement with the inability of FhTE-stimulated splenocytes to produce IFN $\gamma$. 
A
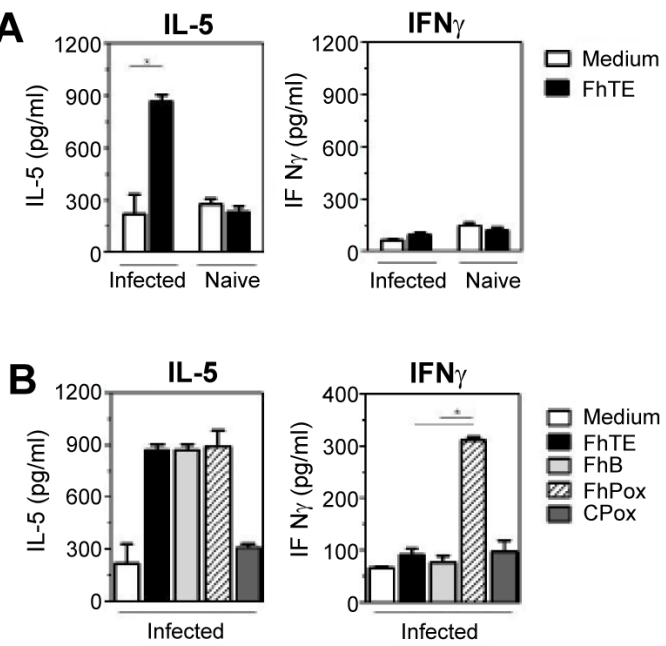

Figure 1: Periodate-treatment of $F$. hepatica total lysate (FhPox) enables the production of IFN $\gamma$ by splenocytes from infected animals. A) Splenocytes from infected or naïve animals were stimulated in vitro with total lysate FhTE $(75 \mu \mathrm{g} / \mathrm{ml})$ for $72 \mathrm{~h}$ at $37^{\circ} \mathrm{C}$. IFN $\gamma$ and IL-5 were detected in culture supernatants by specific ELISA. B) Splenocytes from infected animals were stimulated in vitro with total lysate FhTE $(75 \mathrm{~g} / \mathrm{ml})$, periodate oxidized-lysate (FhPox, $75 \mathrm{~g} / \mathrm{ml}$ ) and incubated for $72 \mathrm{~h}$ at $37^{\circ} \mathrm{C}$. IFN $\Gamma$ and IL-5 were detected in culture supernatants by specific ELISA. Controls consisted in the FhTE lysate incubated only with borhydrure (FhB), or PBS subjected to the complete periodate treatment (CPox). Results are expressed as mean value of triplicates ( \pm SD, indicated by error bars), and are representative of three different experiments. Asterisks represent differences statistically significant $\left({ }^{*} \mathrm{p}<0.01\right)$.

Regarding the phenotyping of myeloid cells, the percentage of CD11chigh $\left(\mathrm{CD} 11 \mathrm{c} \mathrm{ch}^{\mathrm{hi}}\right)$ cells was decreased in the spleens of infected animals (Figure $2 \mathrm{~A}$ ), while they were augmented in the peritoneal cavity (Figure 2B), suggesting that DCs are recruited to the peritoneum. On the other hand, the percentage of $\mathrm{CD} 11 \mathrm{~b}^{+} / \mathrm{F} 4 / 80^{+}$ cells was increased in the peritoneal cavity, indicating a recruitment of macrophages to the peritoneum (Figure 2B). Furthermore, CD11b ${ }^{+}$ Siglec $\mathrm{F}^{+}$cells were augmented both in the spleen and in the peritoneal cavity of infected mice, which would account for the production of IL-5 on stimulated splenocytes. No significant changes were observed

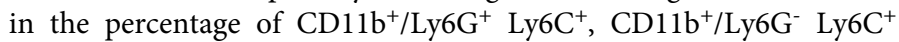
cells (Figure 2).

\section{F. hepatica induces a semi-mature phenotype of DCs during infection}

Previous in vitro reports have shown that parasite products from $F$. hepatica suppress maturation and function of bone marrow DCs (BMDCs) [9-10]. Thus, we investigated in vivo the maturation status of DCs from infected animals. After three weeks of infection, infected $\mathrm{BALB} / \mathrm{c}$ mice presented $\mathrm{CD} 11 \mathrm{c}^{\text {hi }}$ cells in the peritoneum that were characterized by an up-regulation of CD80 and CD86 expression, and a down-regulation of MHC class II expression, as compared to naïve mice (Figure 3A). MHC class II was also decreased on CD11 $\mathrm{c}^{\text {hi }}$ cells in the spleen, while the other co-stimulatory markers were unchanged (Figure 3B). CD11 $\mathrm{c}^{\text {hi }}$ cells from C57BL/6 mice behaved essentially in a similar way except for the fact that CD11chi cells from spleens of infected animals showed similar levels of MHCII expression than naïve mice, while they down-regulated CD40 expression (Figure 3CD). These results suggest that DCs adopt a semi-mature phenotype during infection with $F$. hepatica, characterized by a reduced expression of MHC class II on their surface.

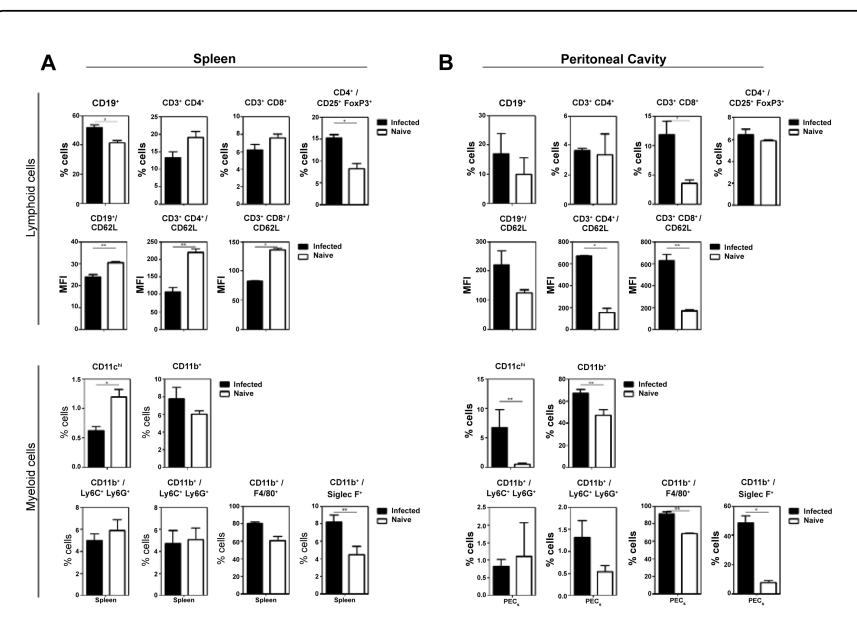

Figure 2: Immunophenotyping of cells from the spleen or peritoneum from $F$. hepatica- infected or naïve mice. BALB/c mice were challenged with 5 metacercariae and after three weeks from infection, splenocytes (A) and PECs (B) were removed, incubated with specific antibodies, and analyzed by flow cytometry. Fifty thousand events were collected and gated on FSC vs SSC dot plot. For the identification of granulocytes or macrophages, cells were first gated on $\mathrm{CD}_{11} \mathrm{~b}^{+}$dots; and for $\mathrm{T}_{\text {regs }}$, cells were first gated on $\mathrm{CD}^{+}$, and then double positive dots for CD25 and Foxp3 were gated. Results are expressed as mean value of triplicates $( \pm \mathrm{SD}$, indicated by error bars), each value meaning a single mouse and are representative of two different experiments. Asterisks represent differences statistically significant $\left({ }^{*} \mathrm{p}<0.01,{ }^{* *} \mathrm{p}<0.05\right)$.

\section{F. hepatica glycans modulate DC-maturation}

In agreement with previous evidences indicating that parasite products from $F$. hepatica can partially inhibit TLR-induced maturation [8-10], BMDCs co-incubated with a parasite total extract (FhTE) and with zymosan (ligand for TLR2), poly:(IC) (TLR3 agonist) or LPS (TLR4 ligand), produced lower levels of IL-12/23p40 than the cell stimulated with the TLR ligand alone (Figure 4A). Next, we investigated whether carbohydrate structures produced by $F$. hepatica were involved in the modulation of DCs. When BMDCs were coincubated with FhTE, IL-6 and IL12/23p40 LPS-induced production by DCs was significantly decreased, while the production of IL-10 was incremented (Figure 4B). On the other hand, when BMDCs were cultured in presence of LPS and periodate-treated parasite total lysate (FhPox) the levels of the pro-inflammatory cytokines IL-12/23p40, IL-6 or IL-10 were equivalent to those obtained with LPS alone, partially abolishing the inhibition of the LPS-induced DC maturation by $F$. hepatica (Figure 4B). As expected, the control FhB/LPS behaved essentially in the same way as FhTE/LPS, while the CPox/LPS induced the same levels of cytokine production than the LPS condition. 
Citation: Noya V, Rodriguez E, Cervi L, Giacomini C, Brossard N, et al. (2014) Modulation of Dendritic Cell Maturation by Fasciola hepatica: Implications of glycans and mucins for Vaccine Development. J Vaccines Vaccin 5: 233. doi:10.4172/2157-7560.1000233

Page 5 of 8

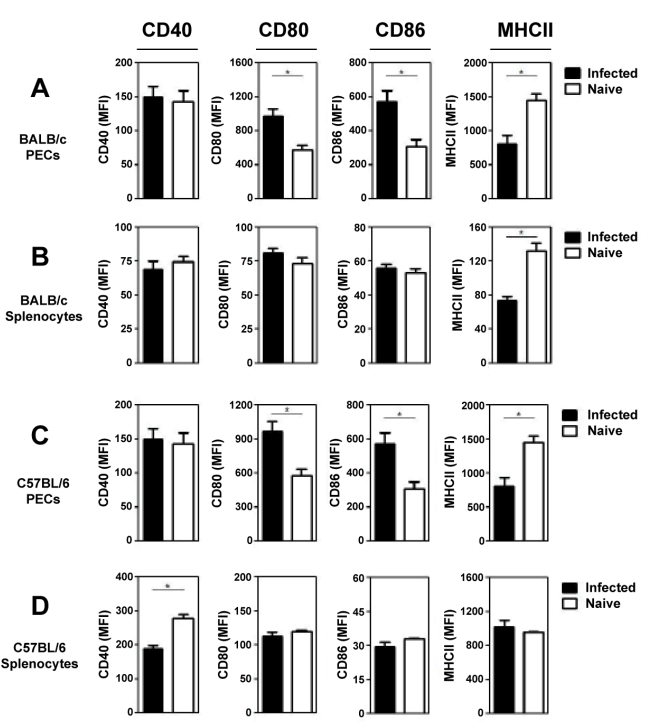

Figure 3: Dendritic cells from infected animals present a semimature phenotype. BALB/c (A-B) or C57BL/6 (C-D) mice were challenged with 5 or 10 metacercariae, respectively, and after three weeks from infection, splenocytes and PECs were removed, and incubated with anti-mouse CD40-FITC, CD80-PeCy5, CD86-APC and MHC-II-PE for $30 \mathrm{~min}$ at $4^{\circ} \mathrm{C}$. Cells were analyzed by flow cytometry. Fifty thousand events were collected and gated on FSC

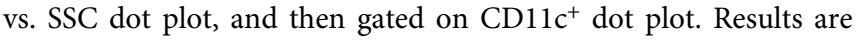
expressed as mean value of quintuplicates $( \pm$ SEM, indicated by error bars), each value meaning a single mouse and are representative of two different experiments. Asterisks represent differences statistically significant $\left({ }^{*} \mathrm{p}<0.01\right)$.

\section{A mucin-like peptide from $F$. hepatica synergizes with LPS to induce DC-maturation and triggers a $F$. hepatica-specific Th1-like immune response}

Mucin-like molecules expressed by parasites participate in attachment and invasion of host cells among other processes, by providing proteases resistance or avoiding immune recognition $[20,29]$. During a characterization of the transcriptome of $F$. hepatica newly excysted juveniles (NEJ) a cDNA clone coding for a mucin-like protein has been identified [27]. The predicted protein, characterized by repeated Ser and Thr residues predicted to be O-glycosylated, is the most frequent in the juvenile ESTs and was found that it is predominantly expressed by qRT-PCR in the invasive stage [27]. In an attempt to evaluate whether this mucin-like peptide could mount an immune response directed to $F$. hepatica, we immunized mice with a synthetic 66-mer non-glycosylated peptide (referred here as Fhmuc) carrying a partial sequence of the identified mucin. A non-glycosylated Fhmuc peptide was used in order to avoid possible immunosuppressive effects by parasite glycans. To this end, cells from the spleen or the peritoneal cavity of mice immunized i.p. with the Fhmuc peptide were stimulated in vitro with Fhmuc or with parasite derived-molecules (FhTE). PECs mainly reacted to the stimulation both with Fhmuc or parasite products by producing high levels of IFN $\gamma$, in absence of IL-5, while spleen cells did not produce significant levels of either IFN $\gamma$ or IL-5 upon antigen stimulation (Figure $5 \mathrm{~A}$ ).
These data indicate that Fhmuc induces a Th1-like response able to recognize $F$. hepatica antigens.

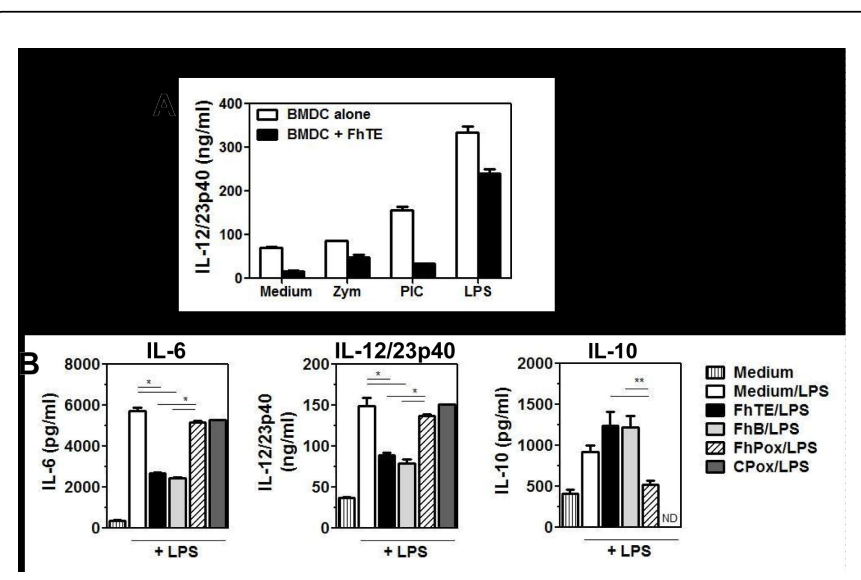

Figure 4: Periodate-treatment of $F$. hepatica total lysate restores the IL-6 and IL-12/23p40 cytokine levels produced by DCs simultaneously treated with FhTE and LPS. A) BMDCs were incubated with FhTE in presence of LPS $(1 \mathrm{~g} / \mathrm{ml})$, Zymosan (1 $\mathrm{g} / \mathrm{ml})$ or poly: (IC) $(50 \mu \mathrm{g} / \mathrm{ml})$ overnight at $37^{\circ} \mathrm{C}$. Then IL-12/23p40 levels were detected on culture supernatants. B) BMDCs were incubated with total lysate FhTE $(75 \mathrm{~g} / \mathrm{ml})$, periodate oxidizedlysate (FhPox, $75 \mathrm{~g} / \mathrm{ml}$ ) in absence or presence of LPS and incubated overnight at $37^{\circ} \mathrm{C}$. Then IL-12/23p 40 levels were detected on culture supernanatants Controls consisted in FhTE lysate incubated only with borhydrure (FhB), or PBS subjected to the complete periodate treatment (CPox). ND stands for "not done". Results are expressed as mean value of triplicates $( \pm \mathrm{SD}$, indicated by error bars), and are representative of three different experiments. Asterisks represent differences statistically significant $\left({ }^{*} \mathrm{p}<0.01,{ }^{* *} \mathrm{p}<0.05\right)$.

Next, we investigated possible pro-inflammatory properties of Fhmuc. Due to the fact that previous data have shown that $F$. hepatica suppresses a protective Th1 response against Bordetella pertussis [30] we sought to study whether Fhmuc could also modify the levels of proinflammatory cytokines induced by LPS in a model of septic shock. Thus, we injected Fhmuc i.p. followed by LPS, and $6 \mathrm{~h}$ later, we evaluated the levels of IL-12/23p40 and IFN $\gamma$ in serum. Control animals were injected with PBS followed by LPS administration. As seen in Figure 5B, sera from animals stimulated with Fhmuc and LPS, presented significant higher levels of IL-12/23p40 and IFN $\gamma$, as compared as to animals inoculated with LPS alone.

Considering the capacity of Fhmuc to synergize with LPS in the production of the pro-inflmmatory cytokines IL-12/23p40 and IFNГ $\gamma$, we then evaluated whether Fhmuc could enhance the maturation of DCs induced by LPS. BMDCs incubated with Fhmuc followed by LPS produced higher levels of IL-12/23p40 or IL-6 than BMDCs stimulated only with LPS. These treated BMDCs, when injected i.p. induced an immune response that recognized parasite products, as detected by the production of IFN $\gamma$ by splenocytes stimulated with Fhmuc or FhTE (Figure 5C). Overall, these data indicate that Fhmuc synergizes with LPS in inducing DC maturation, and that BMDCs loaded with Fhmuc can induce immune responses specific to $F$. hepatica, characterized by high production of IFN $\Gamma$. 

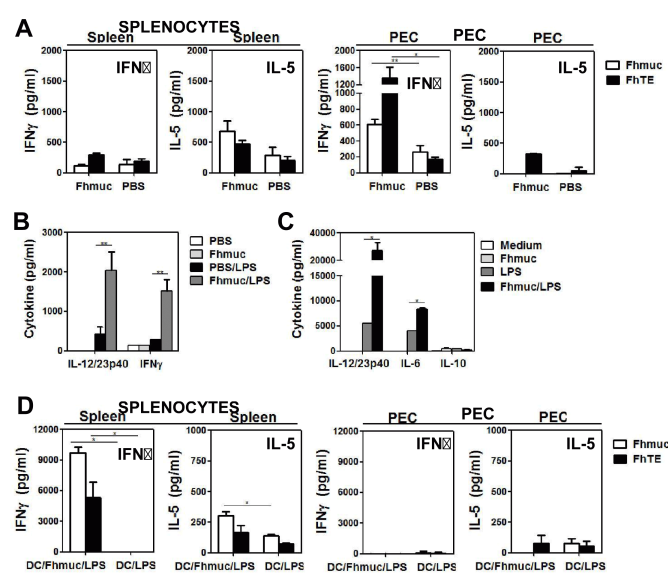

Figure 5: The mucin-like peptide Fhmuc induces specific immune response characterized by a strong production of IFN $\gamma$. A) C57BL/6 mice were immunized i.p. with Fhmuc (10 g) or PBS (control group) at days $0,14,28$. At day 42, spleens and PECs were removed and cultured with Fhmuc peptide $(10 \mu \mathrm{g} / \mathrm{ml})$ or FhTE $(20 \mu \mathrm{g} / \mathrm{ml})$. Secreted cytokines (IFN $\gamma$, IL-5) were tested on culture supernatants by interleukin-specific sandwich ELISA assays. B) Mice were inoculated i.p. Fhmuc $(10 \mu \mathrm{g} / \mathrm{ml})$ and $2 \mathrm{~h}$ later LPS $(1 \mu \mathrm{g} / \mathrm{ml})$ was administrated. IL12/23p40 and IFN $\gamma$ levels were tested in sera after $6 \mathrm{~h}$ of LPS administration. C) BMDCs were incubated with Fhmuc $(10 \mu \mathrm{g} / \mathrm{ml})$ and $2 \mathrm{~h}$ later LPS was added and cells were incubated overnight at $37^{\circ} \mathrm{C}$. Then IL-12/23p40, IL-6 and IL-10 levels were detected on culture supernatants. D) BMDCs treated with Fhmuc and LPS overnight at $37^{\circ} \mathrm{C}$ were washed and inoculated i.p. at $1 \times 10^{6}$ cells/mouse. Ten days later, spleens and PECs were removed and cultured in the presence of Fhmuc $(10 \mu \mathrm{g} / \mathrm{ml})$ or FhTE $(50 \mu \mathrm{g} / \mathrm{ml})$. IFN $\gamma$ or IL- 5 was detected on culture supernatants by specific ELISA. Results are expressed as mean value of triplicates $( \pm S D$, indicated by error bars) and are representative of two different experiments. Asterisks represent differences statistically significant $\left({ }^{*} \mathrm{p}<0.01,{ }^{*} \mathrm{p}<0.05\right)$

\section{Discussion}

In this work we show that $F$. hepatica is able to modulate the immune response of its host at different levels. First, we confirm that macrophages and eosinophils are recruited to the periotoneal cavity as previously described by Walsh and collaborators [2]. Additionally, we show that $\mathrm{T}_{\text {regs }}$ are augmented in the spleen of infected animals. Moreover, we show that there is an increase of DCs in the peritoneum characterized by a semi-mature phenotype associated to an important decrease of MHC class II expression and an up-regulation of the costimulatory molecules CD80 and CD86. The expression of MHC class II-peptide complexes on the surface of DCs is essential for their ability to activate $\mathrm{CD}^{+}{ }^{+} \mathrm{T}$ cells efficiently. Apparently, DCs from F. hepaticainfected animals would present a reduced capacity of antigen presentation to prime specific $\mathrm{CD}^{+}{ }^{+} \mathrm{T}$ cells, as suggested by the low levels of MHC class II expression on DCs. It has been previously shown that ubiquitination of MHCII-peptide complexes regulates their surface expression, retention and degradation in DCs [31-33], and that certain pathogens, such as Salmonella typhimurium, induce polyubiquitination of HLA-DR, resulting in a reduced surface expression of all MHC class II isotypes [34]. On the other hand, there are evidences reporting that Mycobacterium tuberculosis diminishes MHC-II synthesis by macrophages [35] in a process dependent on TLR2 ligation [36], limiting antigen presentation. It would be interesting to evaluate whether any of these molecular mechanisms underlie the reduced expression of MHC class II on the surface of DCs from $F$. hepatica-infected animals.

We also provide evidence indicating that glycan structures from $F$. hepatica are responsible, at least in part, for inhibiting LPS-induced DC maturation and production of IFN $\gamma$ by splenocytes from infected animals. Clearly, these results indicate that the development of a vaccine involving oxidized parasite glycoconjugates, or even DCs loaded with those molecules, would constitute a useful strategy for the design of vaccines against fasciolosis. Parasite glycans, and in particular from helminths, mediate diverse functions that might involve infectivity and pathogenesis, or immune evasion mechanisms. For instance, Schistosoma mansoni, through a glycosylated RNAse that is recognized by the mannose receptor on DCs, impairs protein synthesis of IL-12 by degrading both ribosomal and messenger RNA, leading to a Th2-polorized T-cell response [37]. On the other hand, glycans from the nematode Brugia malayi were reported to participate in the induction of the specific Th2 immune response, since sodium periodate-treated soluble extracts from these parasite induced lower levels of IL-4 by specific lymph node cells [38]. Also, the glycans of the whipworm Trichuris suis mediate the suppression of TNFa production by DCs stimulated with LPS [39]. Helminth glycans are recognized by C-type lectins on DCs, which might in turn suppress TLR signaling [40]. Indeed $T$. suis glycans interact with the mannose receptor, DC-SIGN and MGL, which recognized mannose residues or terminal GalNAc, respectively [39].

Regarding $F$. hepatica glycans, their role in alternative activation of macrophages has been reported by treating glycans with periodate [13] or by inhibiting macrophage binding using antibodies specific for Ctype lectin receptors [22], although no evidence is available about their function on DC maturation. Here, we show that glycans from $F$. hepatica are involved in the modulation of LPS-induced maturation of DCs and that their oxidation restores the capacity of LPS-treated DCs to secrete high levels of the pro-inflammatory cytokines IL-6 and IL-12 and low levels of the anti-inflammatory cytokine IL-10. We are currently working on the identification of these glycans and the C-type lectin receptors on DCs that participate in their recognition.

On the other hand, we show that a mucin-like peptide from $F$. hepatica (Fhmuc) is able to synergize with LPS in inducing DCmaturation, and that it induces a $\mathrm{T}$ cell response specific for $F$. hepatica, both alone or in combination with DCs. The fact that this peptide was identified to be highly expressed in the NEJ infective stage of the parasite, suggests that it could be a good vaccine candidate, since a vaccine targeting the NEJ, able to suppress or eliminate invasion of the liver parenchyma, would minimize liver pathology and reduce production loses in livestock.

Up to date, vaccination assays with either purified native or recombinant proteins from $F$. hepatica, have been carried out mostly using proteases, hemoglobin, glutathione S-transferase or fatty acid binding proteins as immunogens [41]. These studies provided a diverse range of protection $(30-80 \%)$, in ruminants. Interestingly, the protection level was augmented when used a combination of two different cathepsins (CL1 and CL2), comparing to the use of the proteases alone ( $60 \%$ versus $34 \%$ of protection) [42]. Thus, the use of one of these already evaluated immunogens together with a pro- 
inflammatory antigen highly expressed in the infective stage of the parasite, such as Fhmuc, might constitute an attractive alternative to augment the level of protection. At the moment, we are evaluating the capacity of Fhmuc-loaded DC to induce specific cellular immunity against $F$. hepatica and its potential of protecting from liver damage.

In conclusion, this paper highlights the importance of glycans in driving Th2-like immune responses by $F$. hepatica and in modulating TLR-induced maturation of DCs. Furthermore, we present a mucinlike peptide from $F$. hepatica, that induces specific immune responses and that is able to synergize with LPS in inducing pro-inflammatory cytokines by matured DCs. These data might contribute to the understanding of the mechanisms that $F$. hepatica uses to modulate the host immune response, and to the design of vaccines against fasciolosis. We are currently evaluating the protective potential against fasciolosis in mice vaccinated with Fhmuc-DC.

\section{Acknowledgements}

We are especially thankful to the following abattoirs: "Figorífico Carrasco" and "Frigrorífico Sarubbi", for their help during the recollection of worms. This work was supported by grants from Agencia Nacional de Investigación e Innovación (ANII, Uruguay) and Comisión Sectorial de Investigación Científica (CSIC, Universidad de la República, Uruguay). VN and ER were supported by CSIC and ANII, respectively.

\section{References}

1. Rojo-Vázquez FA, Meana A, Valcárcel F, Martínez-Valladares M (2012) Update on trematode infections in sheep. Vet Parasitol 189: 15-38.

2. Walsh KP, Brady MT, Finlay CM, Boon L, Mills KH (2009) Infection with a helminth parasite attenuates autoimmunity through TGF-betamediated suppression of Th17 and Th1 responses. J Immunol 183: 1577-1586.

3. Donnelly S, Stack CM, O'Neill SM, Sayed AA, Williams DL, et al. (2008) Helminth 2-Cys peroxiredoxin drives Th2 responses through a mechanism involving alternatively activated macrophages. FASEB J 22: 4022-4032.

4. Flynn RJ, Mannion C, Golden O, Hacariz O, Mulcahy G (2007) Experimental Fasciola hepatica infection alters responses to tests used for diagnosis of bovine tuberculosis. Infect Immun 75: 1373-1381.

5. O'Neill SM, Brady MT, Callanan JJ, Mulcahy G, Joyce P, et al. (2000) Fasciola hepatica infection downregulates Th1 responses in mice. Parasite Immunol 22: 147-155.

6. Flynn R, Mulcahy G (2008) The roles of IL-10 and TGF-beta in controlling IL-4 and IFN $\gamma$-gamma production during experimental Fasciola hepatica infection. Int J Parasitol 38: 1673-1680.

7. Claridge J, Diggle P, McCann CM, Mulcahy G, Flynn R, et al. (2012) Fasciola hepatica is associated with the failure to detect bovine tuberculosis in dairy cattle. Nat Commun 3: 853.

8. Dowling D, Hamilton C, Donnelly S, La Course J, Brophy P, et al. (2010) Major secretory antigens of the helminth Fasciola hepatica activate a suppressive dendritic cell phenotype that attenuates Th17 cells but fails to activate Th2 immune responses. Infect Immun 78: 793-801.

9. Hamilton CM, Dowling DJ, Loscher CE, Morphew RM, Brophy PM, et al. (2009) The Fasciola hepatica tegumental antigen suppresses dendritic cell maturation and function. Infect Immun 77: 2488-2498.

10. Falcón C, Carranza F, Martínez FF, Knubel CP, Masih DT, et al. (2010) Excretory-secretory products (ESP) from Fasciola hepatica induce tolerogenic properties in myeloid dendritic cells. Vet Immunol Immunopathol 137: 36-46.
11. Vukman KV, Adams PN, Dowling D, Metz M, Maurer M, et al. (2013) The effects of Fasciola hepatica tegumental antigens on mast cell function. Int J Parasitol 43: 531-539.

12. Vukman KV, Adams PN, Metz M, Maurer M, O'Neill SM (2013) Fasciola hepatica tegumental coat impairs mast cells' ability to drive Th1 immune responses. J Immunol 190: 2873-2879.

13. Flynn RJ, Mulcahy G (2008) Possible role for Toll-like receptors in interaction of Fasciola hepatica excretory/secretory products with bovine macrophages. Infect Immun 76: 678-684.

14. Berasain P, Carmona C, Frangione B, Dalton JP, Goñi F (2000) Fasciola hepatica: parasite-secreted proteinases degrade all human IgG subclasses: determination of the specific cleavage sites and identification of the immunoglobulin fragments produced. Exp Parasitol 94: 99-110.

15. Serradell M, Guasconi L, Masih D (2009) Involvement of a mitochondrial pathway and key role of hydrogen peroxide during eosinophil apoptosis induced by excretory-secretory products from Fasciola hepatica. Mol Biochem Parasitol 163: 95-106.

16. Guasconi L, Serradell MC, Masih DT (2012) Fasciola hepatica products induce apoptosis of peritoneal macrophages. Vet Immunol Immunopathol 148: 359-363.

17. Steinman RM (2012) Decisions about dendritic cells: past, present, and future. Annu Rev Immunol 30: 1-22.

18. White RR, Artavanis-Tsakonas K (2012) How helminths use excretory secretory fractions to modulate dendritic cells. Virulence 3: 668-677.

19. Cummings R, Turco S. (2009) Parasitic Infections. In Varki A, Cummings RD, Esko JD, Freeze HH, Stanley P, Bertozzi CR, Hart GW, Etzler ME, editors. Essentials of Glycobiology. (2n edn.), Cold Spring Harbor Laboratory Press, USA.

20. Paveley R, Aynsley S, Turner J, Bourke C, Jenkins S, et al. (2011) The Mannose Receptor (CD206) is an important pattern recognition receptor (PRR) in the detection of the infective stage of the helminth Schistosoma mansoni and modulates IFN $\gamma$ production. Int J Parasitol 41: 1335-1345.

21. Theodoropoulos G, Hicks SJ, Corfield AP, Miller BG, Carrington SD (2001) The role of mucins in host-parasite interactions: Part II - helminth parasites. Trends Parasitol 17: 130-135.

22. Guasconi L, Serradell MC, Garro AP, Iacobelli L, Masih DT (2011) Ctype lectins on macrophages participate in the immunomodulatory response to Fasciola hepatica products. Immunology 133: 386-396.

23. Georgieva K, Georgieva S, Mizinska Y, Stoitsova SR (2012) Fasciola hepatica miracidia: lectin binding and stimulation of in vitro miracidium-to-sporocyst transformation. Acta Parasitol 57: 46-52.

24. McAllister HC, Nisbet AJ, Skuce PJ, Knox DP (2011) Using lectins to identify hidden antigens in Fasciola hepatica. J Helminthol 85: 121-127.

25. Wuhrer M, Grimm C, Dennis R, Idris M, Geyer R (2004) The parasitic trematode Fasciola hepatica exhibits mammalian-type glycolipids as well as Gal(beta1-6)Gal-terminating glycolipids that account for cestode serological cross-reactivity. Glycobiology 14: 115-126.

26. Freire T, Casaravilla C, Carmona C, Osinaga E (2003) Mucin-type Oglycosylation in Fasciola hepatica: characterisation of carcinomaassociated Tn and sialyl-Tn antigens and evaluation of UDPGalNAc:polypeptide $\mathrm{N}$-acetylgalactosaminyltransferase activity. Int J Parasitol 33: 47-56.

27. Cancela M, Ruétalo N, Dell'Oca N, da Silva E, Smircich P, et al. (2010) Survey of transcripts expressed by the invasive juvenile stage of the liver fluke Fasciola hepatica. BMC Genomics 11: 227.

28. Khoo KH, Dell A (2001) Glycoconjugates from parasitic helminths: structure diversity and immunobiological implications. Adv Exp Med Biol 491: 185-205.

29. Tundup S, Srivastava L, Harn DA Jr (2012) Polarization of host immune responses by helminth-expressed glycans. Ann N Y Acad Sci 1253: E1-1E13.

30. Brady MT, O'Neill SM, Dalton JP, Mills KH (1999) Fasciola hepatica suppresses a protective Th1 response against Bordetella pertussis. Infect Immun 67: 5372-5378. 
Citation: Noya V, Rodriguez E, Cervi L, Giacomini C, Brossard N, et al. (2014) Modulation of Dendritic Cell Maturation by Fasciola hepatica: Implications of glycans and mucins for Vaccine Development. J Vaccines Vaccin 5: 233. doi:10.4172/2157-7560.1000233

Page 8 of 8

31. Walseng E, Furuta K, Bosch B, Weih KA, Matsuki Y, et al. (2010) Ubiquitination regulates $\mathrm{MHC}$ class II-peptide complex retention and degradation in dendritic cells. Proc Natl Acad Sci U S A 107: 20465-20470.

32. Walseng E, Furuta K, Goldszmid RS, Weih KA, Sher A, et al. (2010) Dendritic cell activation prevents MHC class II ubiquitination and promotes MHC class II survival regardless of the activation stimulus. J Biol Chem 285: 41749-41754.

33. Shin JS, Ebersold M, Pypaert M, Delamarre L, Hartley A, et al. (2006) Surface expression of MHC class II in dendritic cells is controlled by regulated ubiquitination. Nature 444: 115-118.

34. Lapaque N, Hutchinson JL, Jones DC, Méresse S, Holden DW, et al (2009) Salmonella regulates polyubiquitination and surface expression of MHC class II antigens. Proc Natl Acad Sci U S A 106: 14052-14057.

35. Noss EH, Harding CV, Boom WH (2000) Mycobacterium tuberculosis inhibits MHC class II antigen processing in murine bone marrow macrophages. Cell Immunol 201: 63-74.

36. Harding CV, Boom WH (2010) Regulation of antigen presentation by Mycobacterium tuberculosis: a role for Toll-like receptors. Nat Rev Microbiol 8: 296-307.
37. Everts B, Hussaarts L, Driessen NN, Meevissen MH, Schramm G, et al. (2012) Schistosome-derived omega-1 drives Th2 polarization by suppressing protein synthesis following internalization by the mannose receptor. J Exp Med 209: 1753-1767, S1.

38. Tawill S, Le Goff L, Ali F, Blaxter M, Allen JE (2004) Both free-living and parasitic nematodes induce a characteristic Th2 response that is dependent on the presence of intact glycans. Infect Immun 72: 398-407.

39. Klaver EJ, Kuijk LM, Laan LC, Kringel H, van Vliet SJ, et al. (2013) Trichuris suis-induced modulation of human dendritic cell function is glycan-mediated. Int J Parasitol 43: 191-200.

40. van Die I, Cummings RD (2010) Glycan gimmickry by parasitic helminths: a strategy for modulating the host immune response? Glycobiology 20: 2-12.

41. Hillyer GV (2005) Fasciola antigens as vaccines against fascioliasis and schistosomiasis. J Helminthol 79: 241-247.

42. Piacenza L, Acosta D, Basmadjian I, Dalton J, Carmona C (1999) Vaccination with cathepsin $\mathrm{L}$ proteinases and with leucine aminopeptidase induces high levels of protection against fascioliasis in sheep. Infect Immun 67: 1954-1961. 